\title{
Clinicopathological analysis of 55 cases of ocular surface squamous neoplasia
}

\author{
Kabra RC ${ }^{1}$, Morawala $A^{2}$, Maheshwari $\mathbf{V N}^{3}$ \\ ${ }^{1}$ Dr Ruchi C Kabra, Assistant Professor, Department of Ophthalmology, ${ }^{2}$ Dr A Morawala, Resident Doctor, Department of \\ Ophthalmology, ${ }^{3}$ Dr V N Maheshwari, Resident Doctor, Department of Ophthalmology.
}

Address for Correspondece: Dr. Ruchi C. Kabra, 603, Madhuram Tower, Circuit House Road, Opp State Guest House, Shahibaugh, Ahmedabad, Gujarat, India. E-mail: drruchis@yahoo.co.in

\begin{abstract}
Introduction: The aim of this observational study is to review the presenting clinical features and histopathology of 55 cases of OSSN, at a tertiary care institute in Western India. Method: The study enrolled patients from the in-patient department. The workup included a detailed history with Slit-lamp examination, clinical photographs and histopathological analysis of tissue samples taken via incisional or en-block excisional biopsy. Results: The mean age of the patients was 38.2 years. $25.4 \%$ of patients were HIV reactive, with an average age of 26.8 years. The most common presenting complaints were redness, watering and foreign body sensation occurring in $59.9 \%$ of the cases. $29 \%$ patients were asymptomatic or presented with complaints of a whitish mass lesion. Morphologically, the commonest lesion was of the Leukoplakic variety (32.72\% of cases). On histopathological analysis, $41.8 \%$ of cases showed intraepithelial carcinoma, with mild dysplasia in a majority of cases. Invasive carcinoma was seen in $58.18 \%$ of cases, with poorly differentiated cells in a majority of them. Conclusion: We conclude from the study that the affected population is younger in our region of the world, than in the West. HIV screening would help identify occult cases of HIV which present only with OSSN. Increased awareness of this disease among ophthalmologists would help ensure an early and definitive diagnosis.
\end{abstract}

Keywords: Ocular Surface, Squamous Neoplasia, Ocular surface squamous neoplasia

\section{Introduction}

Ocular surface squamous neoplasia (OSSN) refers to a spectrum of conjunctival and corneal epithelial disease which includes mild to severe dysplasia, intraepithelial carcinoma, and invasive carcinoma

This term was coined by Lee and Hirst in 1995[1]. The precise etio-pathogenesis of these lesions is not very clear but various postulated risk factors include fair skin, male sex, advancing age, exposure to ultraviolet radiations, cigarette smoking, infection with Human Papilloma virus (HPV) and Human Immunodeficiency Virus (HIV) [28][Fig 1]. OSSN has a relatively high recurrence rate after treatment and may metastasize.

These tumours are considered to be low grade malignancies but invasive lesions can spread to the globe or orbit [9]. They present with different morphological types- leukoplakic, papillary, gelatinous, and nodular or

Manuscript received: $10^{\text {th }}$ February 2016

Reviewed: $24^{\mathrm{h}}$ February 2016

Author Corrected; $8^{\text {th }}$ March 2016

Accepted for Publication: $20^{\text {th }}$ March 2016

Tropical Journal of Ophthalmology and Otolaryngology diffuse lesions. The treatment generally recommended for OSSN is excision of the lesion, with a $4 \mathrm{~mm}$ safe margin, with cryoablation at the edges of resected conjunctiva and base of the lesion. The defect hence created is to be covered with either a conjunctival auto graft or amniotic membrane graft. Topical chemotherapy Mitomycin-C or 5-Flurouracil, local brachytherapy and topical Interferons are used as adjuvant therapy in treating the surface dysplasia and neoplasia depending on the extent and histopathology of the tumour [10-15].

Till date Histopathological assessment remains the gold standard for diagnosis of OSSN. The features have been reviewed in many studies $[1,16,17]$. The histological term Dysplasia, consists of epithelial lesions of the conjunctiva and cornea which are divided into three grades based on the thickness of intraepithelial involvement. Cytology shows squamous cells with enlarged nuclei bearing fine to coarse granulation of the nuclear chromatins, irregular nuclear borders, scant cytoplasm. The background is clean. The histopathological classification of various grades of OSSN includes: Mild dysplasia: Dysplastic cells restricted to the lower one-third of the epithelial layer.

Available online at: www.medresearch.in 10 |P a g e 


\section{Original Research Article}

Moderate dysplasia: Dysplastic cells occupying two thirds of the thickness of epithelium. Severe dysplasia / Carcinoma-in-situ: Complete involvement of the epithelium including surface layer without breach of the basement membrane. Cytological observations show variable numbers of dysplastic cells with an admixture of intact and well preserved malignant cells are seen. Invasive squamous cell carcinoma: Breach of the basement membrane with involvement of the substantia propria by tumour cells. Marked cytological aberration with bizarre malignant cell features including tadpole cells with cytoplasmic tails, fibre or spindle cells, hyperkeratinized cells with opaque refractile red or orange cytoplasm, and malignant nuclei are seen. The aim of this study is to review in detail, the presenting clinical features and histopathology of 55 cases of OSSN, operated for incisional or excisional biopsy at our institute, so as to establish data that may be representative of a Western Indian population.

\section{Materials and Methods}

This observational case series was conducted at a tertiary care centre, Regional Institute of Ophthalmology. All patients enrolled in the in-patient department between April 2009 and March 2014 with histopathologically proven OSSN (diagnosed by the affiliated pathology department), were included in the study. Patients with histopathologically proven OSSN but incomplete data were excluded from the study. All the data regarding patient demographics were collected from indoor case records, the clinical slit lamp photographs and ocular pathology laboratory records of the patients. Patient details such as registration number, age and sex of patient were recorded. A detailed history of onset and duration of symptoms was noted. Complete ophthalmological examination including visual acuity testing, slit-lamp examination and posterior segment examination was documented. The morphological appearance of lesions, size and extent was noted from indoor case records and slit lamp photographs. In association with the ocular pathology laboratory, detailed histopathological analysis of the tissue slides was done and the data recorded. In doubtful cases, repeat sections from the available blocks were taken, and the slides were re-examined. OSSN positive tissues were divided into two broad categories: intraepithelial and invasive, depending on the integrity of the basement membrane. The various sections taken from the tumor showed hyperplastic stratified squamous epithelium. The epithelial cells showed dense hyperchromatic nuclei, scanty cytoplasm, loss of polarity and mitotic figures. The presence of an intact basement membrane suggested that the tumor is non-invasive. In some sections we appreciated there was a breach in continuity of basement membrane along with the hyperplastic and dysplastic epithelium. Presence of Keratin pearls below the basement membrane pointed to the invasive variant of Ocular Surface Squamous Neoplasia. All cases in which the integrity of basement membrane was preserved formed the non-invasive neoplasia. They were further separated into mild, moderate and severe dysplasia depending on the thickness of epithelium involved. The invasive variant was divided into categories of well, moderately and poorly differentiated squamous cell carcinoma. A note was also made of the different variants of squamous cell carcinoma such as mucoepidermoid or spindle cell carcinoma. The data thus obtained was tabulated and analysed carefully.

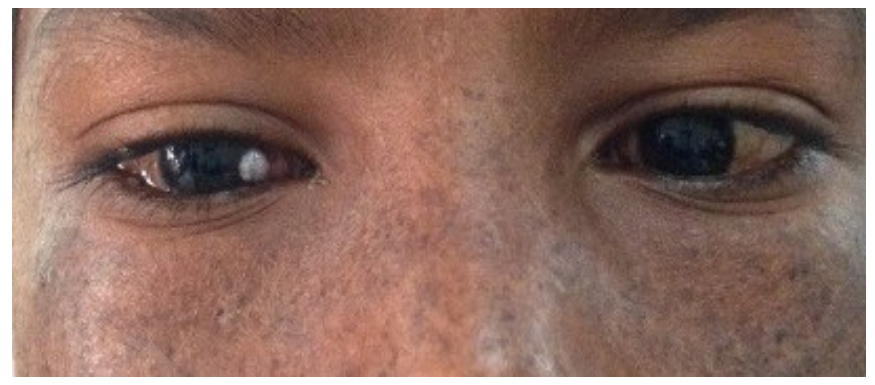

Fig 1: Patient of Xeroderma Pigmentosum with OSSN in Right Eye

\section{Results}

A total of 55 patients who had undergone an incisional or en-block excision biopsy and were histopathologically proven cases of OSSN, were enrolled for the observational study after collection of data.

Age of the patients ranged from 14-72 years with a mean of 38.2 years and median of 39 years. There were 29 patients below 50 years $(52.7 \%)$ and 26 patients aged more than 50 years $(47.2 \%)$.

Among the 55 patients enrolled for the study, 14 were HIV-positive (25.4\%). The mean age of presentation in this group was 26.8 years. There were $47 \mathrm{males}(85.45 \%)$ and 8 female $(14.54 \%)$ patients affected with OSSN. 


\section{Original Research Article}

Redness, watering and foreign body sensations were the most common presenting complains, seen in about59.9\% of the presenting patients. Pain was noted in only $10.40 \%$ of the patients. About $29 \%$ of the patients were either asymptomatic or presented with complaints of a whitish mass in the eye [FIGURE 2].

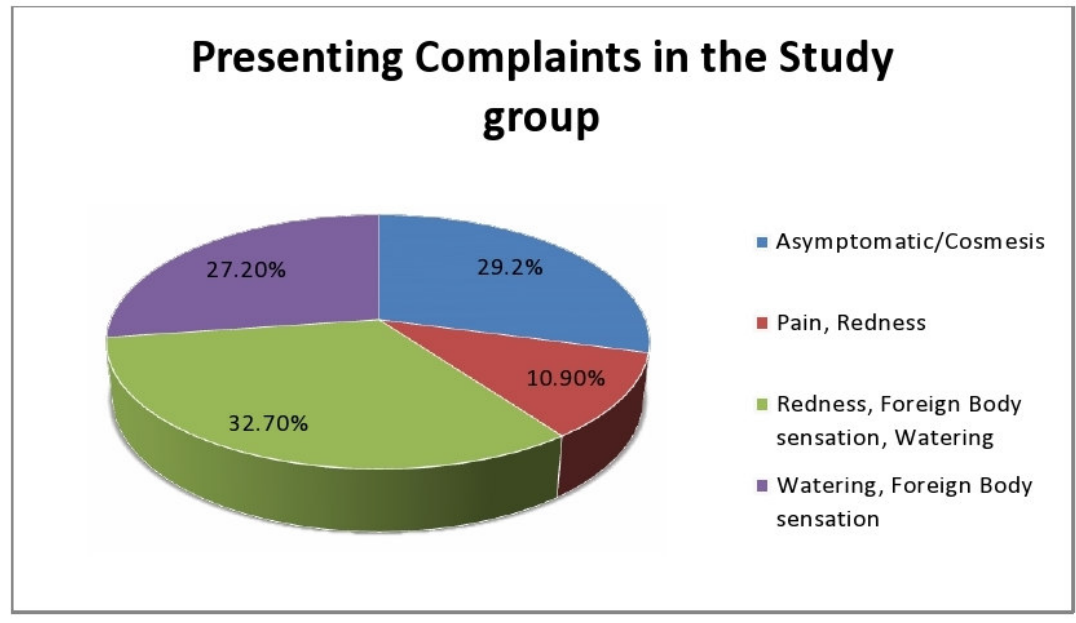

Fig 2: Frequency of presenting complaints in the study group

Morphological examination of the masses on slit lamp examination at the time of presentation revealed leukoplakic lesions in 18 of the cases $(32.72 \%)$ and papillary lesions in $16(29.09 \%)$ cases. The rest of the lesions were either nodular, gelatinous or diffuse in appearance. 17 patients (30.90\%), had a tumour base more than $5 \mathrm{~mm}$ diameter and 38patients (69.09\%) had a tumour base less than or equal to $5 \mathrm{~mm}$ in the maximum diameter at the time of presentation. 51 patients $(92.72 \%)$ had a single foci of the tumour and 4 patients $(7.27 \%)$ had multiple foci of the lesion at presentation.

Analysis of the histopathological data showed that 23patients $(41.81 \%)$ had intraepithelial carcinoma. Maximum number of patients in this group had mild dysplasia. In 32 patients $(58.18 \%)$ there was an invasion and breach in the basement membrane, hence, they were delegated to the group of invasive cell carcinoma.14 patients $(43.75 \%)$ amongst the invasive carcinoma group had poorly differentiated cells[TABLE1].

Table- 1: Morphological characteristics of OSSN lesions in the study group.

\begin{tabular}{|c|c|c|c|}
\hline Parameters & Total patients & Parameters & Total patients \\
\hline \multicolumn{2}{|l|}{ Age } & \multicolumn{2}{|l|}{ Morphological Presentation } \\
\hline$>50$ years & 26 & Papillary & 16 \\
\hline$<=50$ years & 29 & Nodular & 6 \\
\hline \multicolumn{2}{|l|}{ Gender } & Diffuse & 7 \\
\hline Male & 47 & Gelatinous & 8 \\
\hline Female & 8 & Leukoplakia & 18 \\
\hline \multicolumn{2}{|c|}{ Greatest diameter } & \multicolumn{2}{|l|}{ Histopathological diagnosis } \\
\hline$>5 \mathrm{~mm}$ & 17 & \multicolumn{2}{|l|}{ Intraepithelial carcinoma } \\
\hline$<=5 \mathrm{~mm}$ & 38 & Mild dys plasia & 12 \\
\hline \multicolumn{2}{|l|}{ No of lesions } & Moderate dysplasia & 2 \\
\hline Single fod & 51 & Severe dysplasia & 9 \\
\hline Multiple foci & 4 & \multicolumn{2}{|l|}{ Invasive carcinoma } \\
\hline \multicolumn{2}{|c|}{ Fornix involvement } & Well differentiated SCC & 9 \\
\hline Present & 9 & Moderately Differentiated SCC & 9 \\
\hline Absent & 46 & Poorly differentiated SCC & 14 \\
\hline
\end{tabular}




\section{Discussion}

\section{Original Research Article}

To the best of our knowledge this is the first study from Western India on the varied clinicopathological presentations of OSSN. This study represents and summaries the spectra of presentation in patients with OSSN who have been referred for further management to our tertiary care centre. In our study, a majority of patients $(52.7 \%)$ were aged younger than 50 years, and $47.2 \%$ were aged more than 50 years. The mean age was 38.2 years which differs significantly from the average age of incidence of 56 years, in the majority of OSSN cases $[1,19]$.

Some studies mention similar findings, which could be related to that fact that OSSN occurs in a younger population in the equatorial regions of the world, attributable to increased exposure to Ultraviolet radiations [17]. The male preponderance of $85.5 \%$, seen in our study is similar to reports released in the Indian subcontinent as well as in the Western world, including the early reviews of Lee and Hirst [2]. Interestingly, Makupa et al studied a sub-Saharan population in which a female preponderance of patients affected with OSSN, was seen [8].

In the background of HIV infection, Makupa et al also noted that the average affected population seems to be younger [8]. We in our study noted $25.45 \%$ of patients to be affected by HIV. This is less than figures quoted in other studies, which ranged from $71-79 \%$ [21]. In our group of patients, HIV infected cases were significantly younger than the average age group affected by OSSN. We also observed that in 54.5\% patients of HIV, OSSN was the initial presenting clinical feature both ophthalmologic ally and systemically in our OPD, and patients had till then been unaware of their HIV status. ART Centre reference was then done for complete systemic examination, counselling and management of the sero-positive patients. We found a larger number of lesions with a base greater than $5 \mathrm{~mm}$ and with fornicial extension at the time of presentation, in HIV affected population. A related study has been previously published by the authors from the centre on the comparison of clinical factors of OSSN in HIV-affected patients and in patients without HIV infection [18]. Feeder vessels and increased invasiveness were also seen in all HIV infected cases [18]. In a similar study by Makupa et al, an association between feeder vessel and HIV was also noted. They also noted a higher grade of malignancy in HIV infected OSSN population [8][FIGURE 3]. An indolent course of these progressive lesions, along with a younger age of presentations should prompt the ophthalmologist to test for hitherto undiagnosed HIV infection in these patients.

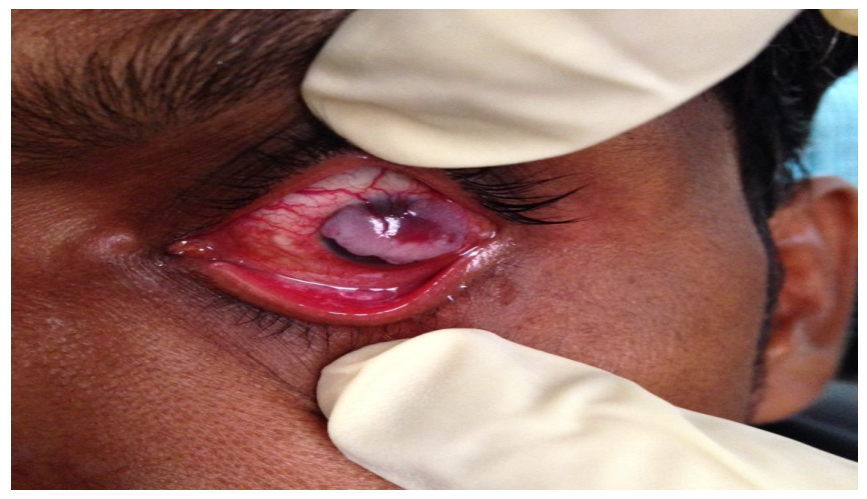

Fig 3 : Large papillary mass approx $11 \mathrm{~mm}$ in diameter enroaching the complete anterior surface of cornea with multiple feeder vessels seen in superior 9 o'clock to 3 o'clock of the limbal area



Fig 4: Leukoplakic growth of approx $2 \mathrm{~mm}$ diameter at limbus with feeder vessel in a 46 year old male patient 


\section{Original Research Article}

Radhakrishnan et al noticed in their study, that OSSN lesions are usually asymptomatic and are detected by chance [19]. About $30 \%$ of the patients in our study were either asymptomatic or had a cosmetic concern. It is nearly impossible to categorise OSSN as benign or malignant based on clinical appearance alone. Most of the studies noticed that OSSN tumours appear as sessile, fleshy, elevated lesion near the limbus in the inter-palpebral region [9][FIGURE 4]. In another study from the Southern part of this country Radhakrishnan et al noticed that out of all the morphological types, the gelatinous type is most common and presents usually as a well-circumscribed raised mass with a smooth surface [19].

We however found a preponderance of leukoplakic (32.72\%) and papillary (29.09\%) lesions in our patients. The gelatinous lesions comprised $14.5 \%$ of the lesions studied. The diffuse morphological type was the least common (12.7\%). A majority of lesions $(92.7 \%)$ in our study consisted of a single focus and the rest $(7.2 \%)$ were multifocal at presentation. In our study, $30 \%$ of the lesions had a tumour base less than/equal to $5 \mathrm{~mm}$ and $70 \%$ had a tumour base greater than $5 \mathrm{~mm}$ on presentation. Some patients had minimal/no ocular symptoms, despite having lesions with a tumour base greater than $5 \mathrm{~mm}$.

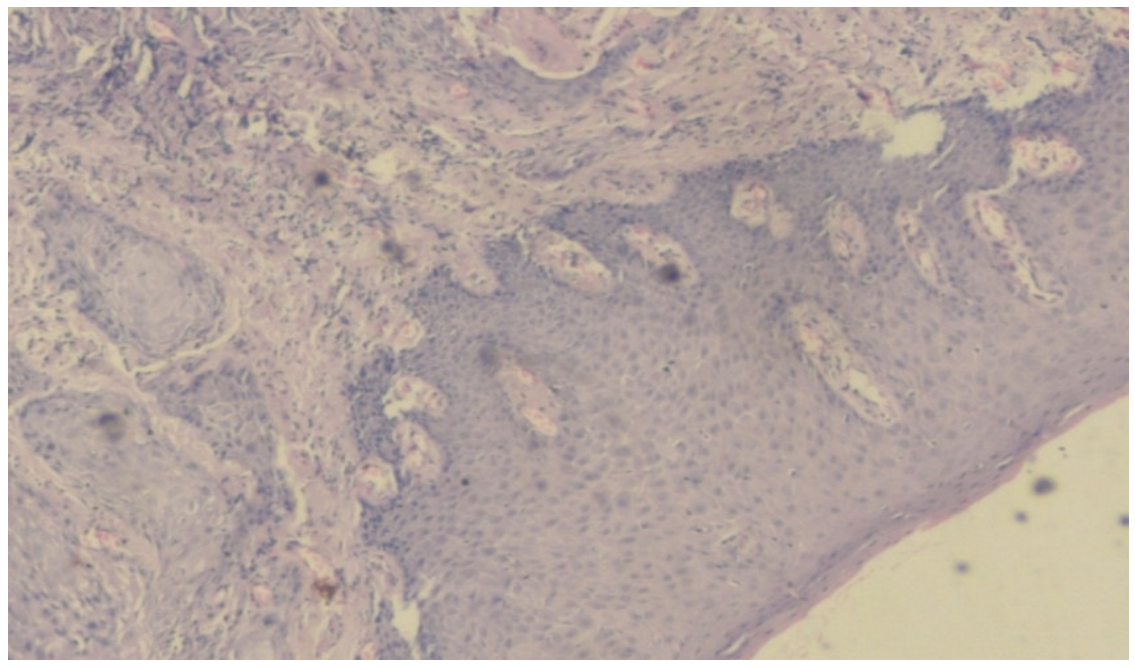

Fig 5: Section shows hyperplastic stratified squamous epithelium with intact basement membrane. Epithelial cells show dense hyperchromatic nuclei and loss of polarity. This suggests severe dysplasia or Carcinoma in-situ. (40x, High power view)

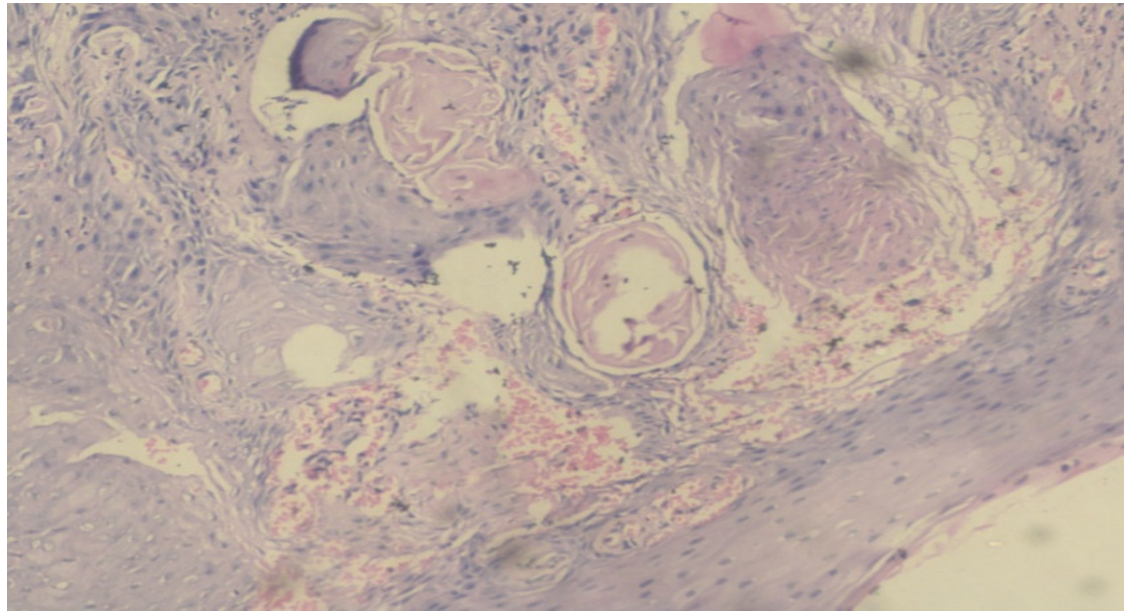

Fig 6: Section shows stratified squamous epithelium invading into underlying stroma. Squamous epithelial cells show hyperchromasia, dysplasia, abnormal mitotic figures and keratin pearls consistent with moderately differentiated squamous cell carcinoma. (10x, Low power view)

On detailed histopathological analysis, lesions that were restricted to the epithelial layer (intraepithelial carcinoma) showed mild cellular dysplasia in a majority of cases (52.1\%) [FIGURE 5]. The lesions of invasive carcinoma which spread beyond the epithelium consisted predominantly of poorly differentiated cells $(43.75 \%)$ [FIGURE 6]. We noticed an almost equal ratio 


\section{Original Research Article}

of invasive and non-invasive tumours. This differs from the findings in a study conducted by Vivekanand and Toopalli et al, in the same subcontinent, in which the proportion of invasive tumours exceeded that of the non-invasive tumours. In contrast to our results, theirs differ in the fact that a majority of the invasive tumours showed well-differentiated cellular morphology, with fewer lesions revealing poorly-differentiated cells [20].

Hence, our observational study of the clinic-morphological and demographic profile of the 55 cases of OSSN from the Western region of the Indian subcontinent, leads us to the following conclusions:

- OSSN affects a younger sub-population in this region as compared to the western world.

- Mandatory HIV screening in patients presenting with suspected OSSN is vital, as a large number of these patients have OSSN as the only presenting feature of AIDS-related disease.

- Because of a large number of patients having minimal symptoms at presentation, a call for increased awareness of this indolent disease is necessary among ophthalmologists, in order to make an early and definitive diagnosis.

Acknowledgement: We acknowledge the immense help received from the scholars whose articles are cited and included in the references of this manuscript. We are also very grateful to all the authors/editors/publishers of all the articles, journals and books from where the literature for this article has been reviewed and discussed.

Funding: Nil, Conflict of interest: Nil

Permission from IRB: Yes

\section{References}

1. Lee, GA. \& Hirst, LW. Ocular surface squamous neoplasia. Surv Ophthalmol. May-Jun,1995; 39 (6): 429-50.

2. Lee, GA.; Williams, G.; Hirst, LW. \& Green, AC. (1994). Risk factors in the development of ocular surface epithelial dysplasia. Ophthalmology. Feb, 1994; 101 (2) : $360-4$

3. Newton, R.; Ferlay, J.; Reeves, G.; Beral, V. \& Parkin, DM. (1996). Effect of ambient solar ultraviolet radiation on incidence of squamous-cell carcinoma of the eye. Lancet. May,1996; 347(9013):1450-1.

4. Napora, C.; Cohen, EJ.; Genvert, GI.; Presson, AC.; Arentsen, JJ.; et al. (1990). Factors associated with conjunctival intraepithelial neoplasia: a case control study. Ophthalmic Surg.Jan,1990; 21(1):27-30.

5. Nakamura, Y.; Mashima, Y.; Kameyama, K.; Mukai, M. \& Oguchi, Y. (1997). Detection of human papilloma virus infection in squamous tumours of the conjunctiva and lacrimal sac by immunohistochemistry, in situ hybridisation, and polymerase chain reaction. $\mathrm{Br} \mathrm{J}$ Ophthalmol. Apr,1997: 81(4):308-13.

6. Sjo, NC.; von Buchwald, C.; Cassonnet, P.; Norrild,B.; Prause, JU.; et al.(2007). Human papilloma virus in normal conjunctival tissue and in conjunctival papilloma: types and frequencies in a large series.Br J Ophthalmol. Aug,2007; 91(8):1014-5.
7. Porges, Y. \& Groisman, GM. (2003). Prevalence of HIV with conjunctival squamous cell neoplasia in an African provincial hospital.Cornea. Jan,2003; 22(1):1-4.

8. Makupa, II.; Swai, B.; Makupa, WU.;White, VA.; Lewallen, S (2012). Clinical factors associated with malignancy and HIV status in patients with ocular surface squamous neoplasia at Kilimanjaro, Christian Medical Centre, Tanzania. Br J Ophthalmol. 2012;96:482-84.

9. Tananuvat N. and Lertprasertsuke N. (2012). Ocular Surface Squamous Neoplasia, Intraepithelial Neoplasia, Dr. Supriya Srivastava (Ed.), In-tech. Rijeka, Croatia DOI: 10.5772/32238. http://www.intechopen. com/ books / intraepithelial-neoplasia / ocular- surface -squamous neoplasia

10. Shields, JA.; Shields, CL.\& De Potter, P. (1997). Surgical management of conjunctival tumors. The 1994 Lynn B. McMahan Lecture. Arch Ophthalmol. Jun,1997; 115 (6):808-15.

11. Chen, C.; Louis, D.; Dodd, T. \& Muecke, J. (2004). Mitomycin $\mathrm{C}$ as an adjunct in the treatment of localised ocular surface squamous neoplasia. Br J Ophthalmol, Jan, 2004; 88(1):17-8.

12. Stone, DU.; Butt, AL. \& Chodosh, J. (2005). Ocular surface squamous neoplasia: a standard of care survey. Cornea.Apr,2005: 24(3):297-300. 


\section{Original Research Article}

13. Al-Barrag, A.; Al-Shaer,M.; Al-Matary,N. \& AlHamdani, M. (2010). 5-Fluorouracil for the treatment of intraepithelial neoplasia and squamous cell carcinoma of the conjunctiva, and cornea.Clin Ophthalmol, July,2010; 4:801-8, ISSN 11775483.

14. Yeatts, RP.; Engelbrecht, NE.; Curry, CD.; Ford, JG. \& Walter, KA. (2000). 5-Fluorouracil for the treatment of intraepithelial neoplasia of the conjunctiva and cornea. Ophthalmology, Dec,2000; 107(12):2190-5.

15. Walsh-Conway, N. \& Conway, RM. (2009). Plaque brachytherapy for the management of ocular surface malignancies with corneoscleral invasion.Clin Experiment Ophthalmol, Aug,2009; 37(6):577-83,http:// onlinelibrary. wiley.com/doi/10.1111/j.1442-9071.2009.02092.x/full

16. Font, RL.; Croxatto, JO. \& Rao, NA. (2006). 'Tumors of the conjunctiva and caruncle. In: Tumors of the eye and ocular adnexa.'(1stedn) SG Silverberg, Washington DC ; 7-10, ISBN 1-881041-99-9

17. Mittal, R., Rath, S., Vemuganti,G.K. (2013). Ocular surface squamous neoplasia - Review of etiopathogenesis and an update on clinicopathological diagnosis. Saudi J Ophthalmol. Jul,2013; 27(3): 177-186.

18. Kabra, RC., Khaitan IA. (2015) Comparative Analysis of Clinical Factors Associated with Ocular Surface Squamous Neoplasia in HIV Infected and Non HIV Patients JCDR.May,2015; 9(5): NC01.

19. Radhakrishnan, A.(2011). Ocular surface squamous neoplasia $-\mathrm{a}$ brief review. Kerala Journal of Ophthalmology. 2011; 23(4). http://www.ksos. in/ ksosjournal / journalsub/Journal_Article_26_468.pdf

20. Toopalli K.; Namala V.; Pandharpukar, M.; Bharadwaj N.; Jayalaxmi, S.; et al. (2014) Ocular Surface Squamous Neoplasia Impression Cytology V/S Histopathology. Sch. J. App. Med. Sci., 2014; 2(1D):461465.http://saspublisher.com/wp-content/uploads/2014/ 03/ SJAMS-21D461-465-c.pdf

21. Nagaiah, G.; Stotler, C.; Orem, J.; Mwanda, W.; Remick, S.;Ocular surface squamous neoplasia in patients with HIV infection in sub-Saharan Africa. Curr Opin Oncol, Sep, 2010; 22 (5): 437-442.

\section{How to cite this article?}

Kabra RC, Morawala A, Maheshwari VN. Clinicopathological analysis of 55 cases of ocular surface squamous neoplasia. Trop J Ophthalmol Otolaryngol.2016;1(1):10-16. doi: 10.17511/jooo.2016.i01.04. 